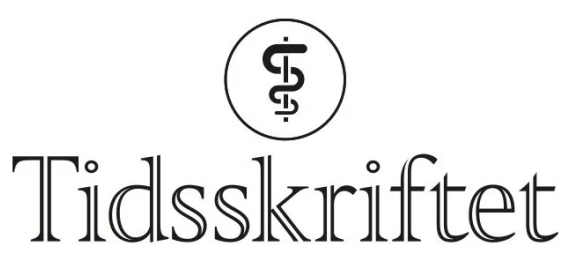

DEN NORSKE LEGEFORENING

\title{
Ionekanalsignaler kan gi medfødt leddstivhet
}

NYHETER

HANNE STØRE VALEUR

Email: hanne.store.valeur@legeforeningen.no

Tidsskriftet

For sterke signaler fra ionekanaler som registrerer bevegelse i fosterlivet kan føre til artrogrypose - medfødt leddstivhet.
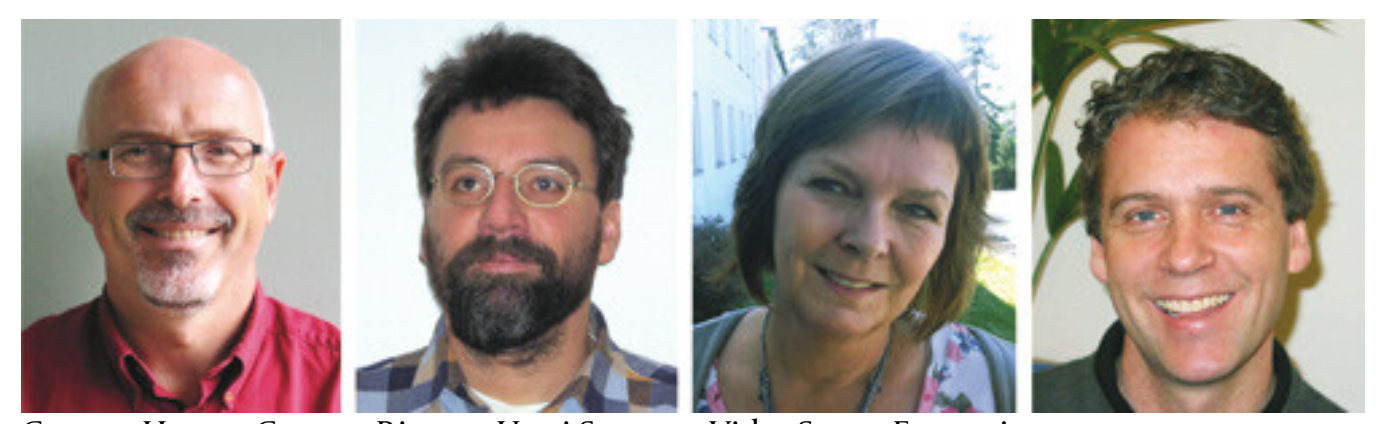

Gunnar Houge, Gunnar Riemer, Unni Steen og Vidar Steen. Foto privat

Artrogrypose er en gruppe medfødte tilstander som kjennetegnes av stive ledd og muskelsvakhet. Normal utvikling av muskler og ledd i fosterlivet forutsetter normal bevegelighet. Alle forstyrrelser som innskrenker fosterets bevegelse kan forårsake artrogrypose. Manglende bevegelse hos fosteret fører til danning av stivt bindevev rundt leddet og innskrenket bevegelighet (1).

Forskere har nå påvist at dominant arvelig artrogrypose kan skyldes mutasjoner i en membranbundet ionekanal kalt PIEZO2 (므). Denne ionekanalen reagerer på bevegelse (strekk) av en celle ved å slippe inn kationer. Normalt motvirker signalet fra ionekanalen overbevegelighet i ledd. Dersom PIEZO2-kanalene er overfølsomme for strekk, fører det til nedsatt bevegelighet i ledd. Kanalen ble nylig beskrevet av en forskergruppe ved Scrippsinstituttet i San Diego.

- Like etter påviste vår forskergruppe en nyoppstått feil i et gen kalt FAM38B hos en norsk kvinne med artrogrypose. Det viste seg at FAM38B kodet for PIEZO2. Vi tok derfor kontakt med forskergruppen i San Diego. De var også blitt kontaktet av en forskergruppe fra 
Harvard som hadde påvist en annen PIEZO2-forandring hos en artrogryposepasient, forteller Gunnar Houge, en av forfatterne av artikkelen som nylig ble publisert i Proceedings of the National Academy of Sciences of the United States of America (PNAS).

Denne kontakten førte til et forskningssamarbeid, og i løpet av få måneder hadde Scrippsgruppen kartlagt den funksjonelle konsekvensen av genforandringene. At overfølsomhet i en bevegelsessensor kan føre til leddstivhet, er prinsipielt nytt. Noen av pasientene med denne mutasjonen mangler korsbånd, noe som indikerer at normal bevegelsesregistrering er nødvendig for normal leddanning hos fosteret. Andre fenotypiske trekk er redusert øyebevegelighet (oftalmoplegi) samt lungebevegelighet (restriktivt mønster ved spirometri), som kan gi pustevansker ved anstrengelse hos enkelte pasienter.

- Siden PIEZO2-kanalen er en ionekanal, kan tilstanden i teorien behandles dersom man klarer å utvikle substanser som hemmer kanalens aktivitet. Det blir også interessant å se om andre mutasjoner i samme gen er assosiert med overbevegelighet (hypermobilitet), som er en langt vanligere tilstand enn artrogrypose, sier Houge. - Vårt senter har nettopp igangsatt et prosjekt for å undersøke om andre norske artrogryposefamilier kan ha PIEZO2mutasjoner.

\section{Genomisk dysregulering}

Gunnar Houge, artikkelens norske førsteforfatter, er seksjonsoverlege ved Senter for medisinsk genetikk ved Haukeland universitetssykehus og leder en forskningsgruppe på genomisk dysregulering. Studien er et resultat av et samarbeid mellom Haukeland universitetssykehus, Harvard University og Scripps Institute. Fra norsk side har samarbeid mellom TRS-kompetansesenter for sjeldne diagnoser på Sunnaas sykehus og de medisinskgenetiske avdelingene i Bergen, Trondheim og Nijmegen vært avgjørende for å lykkes. De andre norske medforfatterne av artikkelen er Unni Steen, Vidar Steen og Gunnar Riemer. 


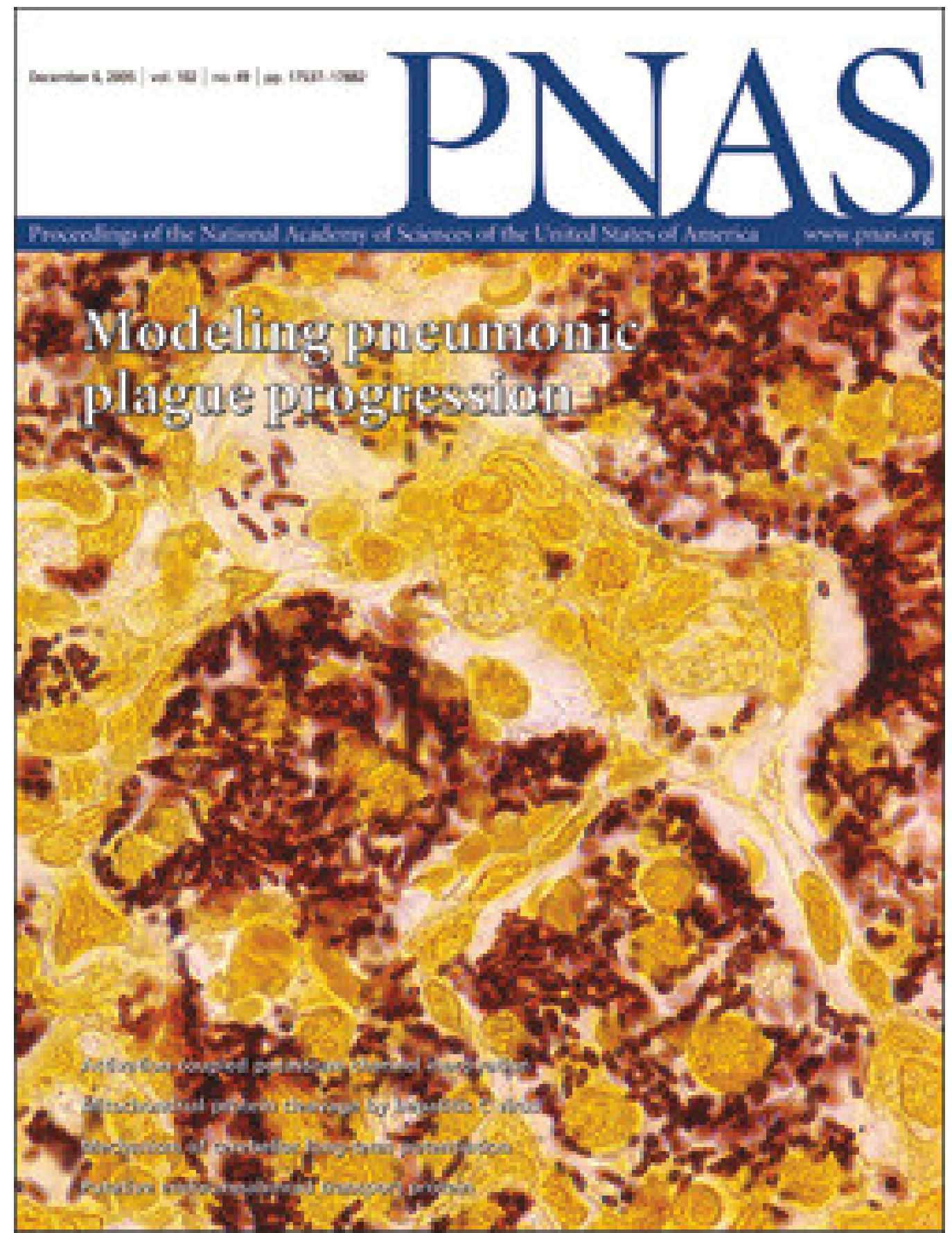

Artikkelen ble e-publisert 4. mars 2013 i det prestisjetunge tidsskriftet Proceedings of the National Academy of Sciences of the United States of America(www.pnas.org)

\section{Ordforklaringer}

Artrogrypose: Ikke-progredierende tilstand med medfødte kontrakturer (stive ledd) i to eller flere ledd i to eller flere regioner av kroppen.

Fenotype: Individets observerbare egenskaper som konsekvens av arv og miljø.

Ionekanal: Et proteinkompleks som danner en kanal i en cellemembran der ladede atomer kan slippes igjennom ved behov.

\section{LITTERATUR}

1. Veileder for oppfølging av AMC. Nesoddtangen: TRS, 2003. www.sunnaas.no/omoss/avdelinger/trs/diagnoser/amc/Documents/TRSAMCveileder25.02.03.pdf (25.6.2013). 
2. Coste B, Houge G, Murray MF et al. Gain-of-function mutations in the mechanically activated ion channel PIEZO2 cause a subtype of Distal Arthrogryposis. Proc Natl Acad Sci U S A 2013; 110: 4667-72. [PubMed] [CrossRef]

Publisert: 20. august 2013. Tidsskr Nor Legeforen. DOI: 10.4045/tidsskr.13.0797

(C) Tidsskrift for Den norske legeforening 2023. Lastet ned fra tidsskriftet.no 26. april 2023. 